\title{
DESKRIPSI KARAKTERISTIK KLIEN HIPERTENSI
}

\author{
Lisbeth Pardede ${ }^{1}$, Renta Sianturi ${ }^{2^{*}}$, Aprillia Veranita ${ }^{3}$ \\ 1. Program Studi S1 Keperawatan, STIKes Mitra Keluarga, Bekasi-Indonesia \\ 2. Program Studi S1 Keperawatan, STIKes Mitra Keluarga, Bekasi-Indonesia \\ 3. Program Studi DIII Keperawatan, STIKes Mitra Keluarga, Bekasi-Indonesia
}

*Korespondensi: Renta Sianturi | STIKes Mitra Keluarga|nersrensi89@gmail.com

\begin{abstract}
Abstrak
Pendahuluan: Hipertensi merupakan jenis penyakit tidak menular (PTM) yang sering di jumpai di Indonesia. Seseorang dikatakan hipertensi apabila tekanan darah systole lebih $140 \mathrm{mmHg}$ dan tekanan darah diastole lebih dari $90 \mathrm{mmHg}$. Banyak faktor yang mempengaruhi terjadinya hipertensi. Faktor tersebut ada yang dapat dimodifikasi dan ada faktor yang tidak dapat dimodifikasi. Beberapa faktor yang tidak dapat dimodifikasi ini termasuk dalam karakteristik responden meliputi usia, jenis kelamin, lama mengalami hipertensi dan Pendidikan sementara karakteristik resoponden yang dapat di modifikasi meliputi indeks massa tubuh, Indeks Massa Tubuh. Tujuan penelitian ini dilakukan agar dapat melihat gambaran karakteristik responden hipertensi.

Metode: Metode penelitian ini yaitu deskriptif cross-sectional. Teknik pengambilan sampling dengan purposive sampling dengan jumlah responden sebanyak 66 orang.

Hasil: Hasil penelitian menunjukan rerata usia responden yaitu 55 tahun, jenis kelamin mayoritas perempuan sebesar $68.2 \%$, lama menderita rerata 7 tahun, rerata IMT 28,89 termasuk dalam obesitas derajat 1 dan Pendidikan mayoritas SMA sebesar $48,5 \%$.
\end{abstract}

Kesimpulan: Karakteristik responden dalam penelitian termasuk dalam golongan beresiko mengalami hipertensi.

Kata Kunci: Karakteristik, Hipertensi, Usia, Jenis kelamin, Indeks Massa Tubuh (IMT).

Diterima 12 Januari 2020; Accepted 30 Juni 2020

\section{PENDAHULUAN}

Penyakit kardiovaskular merupakan salah satu penyebab kematian tertinggi di seluruh dunia. Salah satu penyakit kardiovaskular dengan prevalensi yang tinggi adalah hipertensi. berdasarkan data yang diterbitkan WHO pada tahun 2019, terdapat 1,13 milyar penduduk dunia yang mengalami hipertensi. Hipertensi adalah keadaan dimana terjadi peningkatan tekanan darah sistolik lebih dari $140 \mathrm{mmHg}$ atau tekanan darah diastolik lebih dari $90 \mathrm{mmHg}$ yang diukur dalam 2 kali pengukuran dalam selang waktu 5 menit dan dalam keadaan tenang (Kemenkes, 2015). Pria dan wanita beresiko mengalami hipertensi. Menurut data dari Cheryl, et.al (2017), pria memiliki resiko yang lebih tinggi untuk mengalami hipertensi, yaitu sebesar 30,2 \% dan wanita sebesar $27,7 \%$.

Faktor yang yang mempengaruhi terjadinya hipertensi dikelompokkan menjadi dua, yaitu faktor yang dapat dimodifikasi dan faktor yang tidak dapat dimodifikasi. Faktor yang dapat dimodifikasi adalah diet yang tidak sehat, kurangnya aktivitas fisik, konsumsi tembakau dan alkohol, serta kelebihan berat badan dan obesitas (WHO, 2019). Faktor resiko yang tidak dapat dimodifikasi yaitu riwayat keluarga dengan hipertensi, usia diatas 65 tahun, dan adanya penyakit kronis seperti diabetes melitus dan gagal ginjal (WHO, 2019). Usia sangat mempengaruhi kejadian hipertensi karena pada usia lansia terjadi aging process yang akan mempengaruhi elastisitas pembuluh darah dan penumpukan plak yang berisiko besar untuk mempengaruhi terjadinya hipertensi. Riwayat keluarga mempengaruhi terjadinya hipertensi karena adanya kesamaan gen yang rentan mengalami hipertensi.

Faktor yang dapat dimodifikasi yaitu pola hidup yang akan berdampak terhadap indeks massa tubuh yang merupakan bagian dari karakteristik responden. Indeks massa tubuh (IMT) adalah indikator yang biasanya digunakan untuk mengklasifikasikan kelebihan berat badan dan obesitas pada orang dewasa. kelebihan berat badan adalah seseorang dengan IMT lebih dari 25, sementara obesitas keadaan dimana IMT diatas 30 (WHO, 2019). Berdasarkan penelitian yang dilakukan Kumbara, et.al (2018), kejadian hipertensi lebih tinggi pada individu yang kelebihan berat badan dan obesitas dibandingkan dengan individu dengan IMT normal. Peningkatan usia menjadi salah satu faktor resiko terjadinya hipertensi, dimana terjadi peningkatan kejadian hipertensi, yaitu sebesar 7,5\% pada rentang usia 18-19,33,2 \% pada rentang usia 40-59, dan 63,1 \% pada rentang usia 65 tahun keatas (Cheryl, 2017). Studi ini bertujuan untuk melihat 
gambaran karakteristik penderita hipertensi berdasarkan jenis kelamin, pendidikan, status pernikahan, usia, lama menderita hipertensi, dan IMT.

\section{METODE}

Metode penelitian ini menggunakan yaitu metode deskriptif cross-sectional untuk mengetahui gambaran karakteristik responden yang mengalami hipertensi. Penelitian ini dilakukan di wilayah kerja Puskesmas Pengasinan Bekasi,Provinsi Jawa Barat. Sampel dalam penelitian ini adalah pasien hipertensi yang ada di wilayah kerja Puskesmas Pengasinan. Teknik pengambilan sampel dalam penelitian ini purposive sampling dengan total responden sebesar 66 orang. Pengumpulan data dilakukan dengan melakukan wawancara kepada responden, pengukuran tekanan darah untuk memastikan responden tersebut mengalami hipertensi, kemudian dilakukan pengisian kuesioner karakteristik responden. Data karakteristik responden dikumpulkam kemudian dianalisa secara univariat. Analisa data digunakan dengan program SPSS versi 21 dan penelitian ini sudah mendapatkan persetujuan etik dengan nomor : 03/19.10/0204.

\section{HASIL}

\section{Karakteristik jenis kelamin Penderita Hipertensi di Puskesmas}

Karakteristik responden terdiri dari data numerik dan data kategorik. Data numerik dalam penelitian yaitu usia, lama mengalami hipertensi dan indeks massa tubuh

Tabel 1: karakteristik responden berdasarkan usia, lama hipertensi dan IMT ( $\mathrm{n}=66$ orang)

\begin{tabular}{lccc}
\hline \multicolumn{1}{c}{ Variabel } & Mean & Min-Max & SD \\
\hline Usia & 54,77 & $18-64$ & 8,402 \\
\hline $\begin{array}{l}\text { Lama } \\
\text { menderita } \\
\text { hipertensi }\end{array}$ & 7,14 & $1-16$ & 4,366 \\
\hline IMT & 28,89 & $17,58-33,76$ & 3,93 \\
\hline
\end{tabular}

Tabel 1 menunjukkan bahwa usia responden rata -rata 54,77, lama mengalami hipertensi rata-rata 7 tahun, dan indeks massa tubuh responden rerata $28,89$.

Tabel 2. Distribusi Frekuensi Jenis Kelamin Dan Pendidikan $(n=66$ orang)

\begin{tabular}{lll}
\hline Variabel & Kategori & Frekuensi \\
\hline \multirow{4}{*}{ Jenis Kelamin } & Laki - Laki & $31,8 \%$ \\
& Perempuan & $68,2 \%$ \\
& SD & 30,3 \\
& SMP & $12,1 \%$ \\
& SMA & $48,5 \%$ \\
& SARJANA & $8,1 \%$ \\
\hline
\end{tabular}

Tabel 2 menunjukkan bahwa jenis kelamin mayoritas yaitu perempuan dengan frekuensi $68,2 \%$ dan pendidikan mayoritas SMA sebesar 48,5\%.

\section{PEMBAHASAN}

Penelitian yang dilakukan Buford (2016) dikatakan terdapat beberapa mekanisme utama termasuk peradangan, stres oksidatif, dan disfungsi endotel, proses biologis umum terjadi pada penuaan dan perkembangan hipertensi dan memiliki peran mekanistik utama dalam meningkatnya risiko kardiovaskular dan hipertensi pada usia lanjut. Peradangan adalah respons lokal terhadap cedera jaringan atau infeksi yang membantu dalam perbaikan jaringan yang rusak dan/atau penghancuran agen berbahaya. Terjadinya penurunan fisiologis mengakibatkan rentan terhadap infeksi dan penyakit yang secara dramatis meningkatkan risiko kematian.

Usia responden termasuk kedalam penggolongan lansia awal, yang berarti sudah mulai mengalami aging process. Anggraini (2014) menyebutkan bahwa dengan usia memiliki hubungan signifikan dengan angka kejadian hipertensi. Pertambahan usia akan menyebabkan 2 kali lebih besar mengalami hipertensi. Kelompok usia 25-34 tahun mempunyai risiko hipertensi 1,56 kali dibandingkan usia 18-24 tahun. Risiko 
hipertensi meningkat bermakna sejalan dengan bertambahnya usia dan kelompok usia $>75$ tahun berisiko 11,53 kali (Rahajeng \& Sulistyowati, 2009). Hasil penelitian ini sesuai dengan konsep menyatakan bahwa pada aging proses akan menyebabkan perubahan kontraktilitas jantung dan penurunan elastisitas pembuluh darah sehingga dibutuhkan tekanan yang tinggi untuk mengalirkan darah keseluruh tubuh.

Lama menderita hipertensi pada penelitian ini reratanya selama 6,94 tahun. Hasil penelitian menunjukkan bahwa mengalami hipertensi selama 7 tahun meningkatkan kejadian munculnya ansietas. Ansietas merupakan salah satu faktor penyebab hipertensi, sehingga lama mengalami hipertensi 7 tahun berisiko mengalami komplikasi. Semakin lama mengalami hipertensi maka semakin tinggi resiko mengalami komplikasi (Laksita, 2016).

Penelitian Rahajeng \& Sulistyowati (2009) menyebutkan bahwa klien yang mengalami obesitas meningkatkan 2,79 kali kejadian hipertensi, sementara yang overweight meningkatkan 2,15 kali kejadian hipertensi sedangkan IMT normal 1,44 kali dibandingkan mereka yang kurus. Obesitas abdominal juga mempunyai risiko hipertensi secara bermakna sebesar 1,40 kali. Indeks Massa Tubuh memiliki pengaruh terhadap kejadian hipertensi (Kurniasih \& Muhammad Riza, 2012). Hal ini disebabkan adanya pembentukan plak lemak pada pembuluh darah yang mengakibatkan kekakuan pada dinding pembuluh darah (aterosklerosis) sehingga dibutuhkan tekanan yang tinggi untuk mengalirkan darah keseluruh tubuh

Hasil penelitian yang dilakukan Etal. (2011) dalam Seham (2015) mengatakan bahwa prevalensi hipertensi berdasarkan kelompok usia dan jenis kelamin, terjadi pada dewasa tua. presentasi terdapat pada wanita $(54,45 \%)$, (Hussein, 2018), wanita $(62,8 \%)$, (Wagner, 2018) lebih banyak pada wanita daripada pria. Hal Ini disebabkan karena efek defisiensi hormon pasca menopause dan beberapa faktor risiko seperti obesitas, situasi stres yang lebih berpengaruh pada perempuan daripada laki-laki. Pernyataan ini didukung oleh hasil penelitian Wehedy A., e tal. (2014) dalam Seham (2015) yang mengatakan bahwa, hipertensi lebih banyak ditemui pada wanita daripada pria karena banyak faktor risiko seperti perubahan hormon yang lebih banyak mempengaruhi wanita. Hasil penelitian yang dilakukan oleh Wagner, (2018) dikatakan bahwa wanita dengan Hipertensi dapat menimbulkan keadaan-keadaan patologis yang merugikan seperti hipertrofi ventrikel kiri, disfungsi diastolik, gagal jantung dengan atau tanpa ejeksi fraksi yang menahun, peningkatan kekakuan arteri, diabetes, Chronic Kidney Disease (CKD).

Hasil penelitian yang dilakukan oleh Seham (2015) dikatakan bahwa Pengetahuan dan modifikasi gaya hidup pasien memainkan peran penting dalam mengendalikan hipertensi dan mencegah komplikasi jangka panjang. Bani (2011) dalam Seham (2015) menemukan bahwa hipertensi lazim terjadi di pada orang-orang yang buta huruf, pensiunan, dan orang-orang dengan keluarga besar. Terkait dengan pendidikan sekolah di antara pasien hipertensi, separuh dari pasien hipertensi buta huruf dan seperempat dari mereka adalah perokok. Seham (2015) Perlu adanya program pendidikan yang dapat meningkatkan kesadaran pasien mengenai penyakit hipertensi, agar persepsi berubah tentang modifikasi perilaku gaya hidup untuk mengendalikan hipertensi dan komplikasinya. Li X. Et al. (2013) dalam Seham (2015) mengatakan sebagian besar pasien tidak menyadari kemungkinan komplikasi hipertensi, dapat menyebabkan penyakit ginjal.

Seham (2015) merekomendasikan: 1). Fokus harus pada pendidikan kesehatan masyarakat dalam memahami tekanan darah tinggi dan pengaruhnya terhadap kesehatan mereka untuk membantu mengendalikannya. 2). Penting untuk memahami status pengetahuan pasien saat ini dan persepsi terhadap gaya hidup. modifikasi perilaku sebagai faktor penting dalam mengendalikan hipertensi. 3). mengembangkan program perencanaan kesehatan untuk pasien hipertensi untuk mengendalikan penyakit dan mencegah komplikasinya dan mencegah orang yang tidak hipertensi. 4). Tantangan yang dihadapi pasien hipertensi seperti pendidikan kesehatan kurang, penghasilan yang kekurangan dan jarak dari rumah harus menjadi perhatian.

Seseorang tidak menikah dikaitkan dengan penurunan kelangsungan hidup pada populasi secara umum. Status perkawinan menikah, bercerai, berpisah, janda, atau tidak pernah menikah akan mempengaruhi pasien dengan penyakit kardiovaskular, secara umum belum dipahami dengan baik. Hasil penelitian yang dilakukan oleh Schultz (2017), dikatakan bahwa status perkawinan secara independen ada kaitannya dengan gangguan kardiovaskular pada pasien dengan atau berisiko tinggi penyakit kardiovaskular, dengan mortalitas yang lebih tinggi pada populasi yang belum menikah. 


\section{KESIMPULAN}

Hasil penelitian menunjukkan bahwa gambaran usia responden termasuk dalam penggolongan pralansia, lama mengalami hipertensi termasuk dalam golongan kronik, dan IMT termasuk kegolongan obesitas derajad 1. Sementara frekuensi jenis kelamin mayoritas perempuan dan frekuensi Pendidikan mayoritas SMA tergolong Pendidikan tinggi. Penelitian selanjutnya dapat dilakukan penelitian analisis faktor yang mempengaruhi terjadinya hipertensi.

\section{UCAPAN TERIMA KASIH}

Ucapan terima kasih kepada Kepala Puskesmas Pengasinan Bekasi Timur beserta jajarannya. Pasien hipertensi yang telah bersedia menjadi responden dalam penelitian, Ristekdikti yang memberikan dana dan STIKes Mitra Keluarga yang mewadahi untuk mendapatkan kesempatan melakukan penelitian.

\section{REFERENSI}

Alhawari (2018). Blood Pressure and Its Association with Gender, Body Mass Index, Smoking, and Family History among University Students. International Journal of Hypertension. Volume 2018, Article ID 4186496, 5 pages https://doi.org/10.1155/2018/4186496

Anggraini, Rika. 2014. Hubungan Indeks Massa Tubuh (IMT), Aktivitas Fisik, Rokok, Konsumsi Buah, Sayur Dan Kejadian Hipertensi Pada Lansia Di Pulau Kalimantan. Diambil dari https://digilib.esaunggul.ac.id/hubungan-indeks-massa-tubuh-imt-aktivitas-fisik-rokok-konsumsi-buahsayur-dan-kejadian-hipertensi-pada-lansia-di-pulau-kalimantan-analisis-data-riskesdas-2007-2408.html

Buford (2016). Hypertension and Aging. Ageing Res Rev. 2016 March; 26: 96-111. doi:10.1016/j.arr.2016.01.007.

Cheryl, et. al. (2017). Hypertension Prevalence and Control Among Adults: United States, 2015-2016. NCHS Data Brief, 289

Everett \& Zajacoa (2015). Biodemography Soc Biol. Gender Differences in Hypertension and Hypertension Awareness Among Young Adults. 61(1): 1-17. doi:10.1080/19485565.2014.929488.

Hussein et.,al (2018).Blood Pressure and Its Association with Gender, Body Mass Index, Smoking, and Family History among University Students. Volume 2018, Article ID 4186496, 5 pages. https://doi.org/10.1155/2018/4186496 https://www.hindawi.com/journals/ijhy/2018/4186496

Kemenkes. (2015). Pusat Data dan Informasi Kesehata RI : Hipertensi. Jakarta : Kemenkes

Khusumaningtyas. (2018, February 23). https://lifestyle.kompas.com/read/2018/02/23/173500523/apa-sajakomplikasi-yang-menyertai-hipertensi-

Kumbara, et. al. (2018). Different risk for hypertension, diabetes, dyslipidemia, hyperuricemia according to level of Body Mass Index in Japanese and American subjects. Nutrient, 2-11

Naidu (2019). Factors associated with the severity of hypertension among Malaysian adults. 14(1): e0207472doi: 10.1371/journal.pone.0207472. 2019 Jan

Rahajeng, Ekowati \& Sulistyowati. 2009. Prevalensi Hipertensi dan determinanya di Indonesia. Jurnal Kedokteran Indonesia. $\quad$ Vol. 59 no $12 . \quad$ Diambil dari https://s3.amazonaws.com/academia.edu.documents/41894927/700-760-1 PB.pdf?response-content disposition=inline\%3B\%20filename\%3DPrevalensi_Hipertensi_dan_Determinannya.pdf\&X-AmzAlgorithm=AWS4-HMAC-SHA256\&X-Amz-

Credential=AKIAIWOWYYGZ2Y53UL3A\%2F20191015\%2Fus-east-1\%2Fs3\%2Faws4_request\&XAmz-Date $=20191015 T 100417 Z \& X-A m z-E x p i r e s=3600 \& X-A m z-S i g n e d H e a d e r s=h o s t \& X-A m z-$ Signature $=$ f938a636878dc48891a1861c7ccf6d658c84cfd71c874a94284c5374f8d8242f

Schultz et al (2017). Marital Status and Outcomes in Patients With Cardiovascular Disease. J Am Heart Assoc. 2017;6: e005890. DOI: 10.1161/JAHA.117.005890

Seham et al, (2015). Knowledge and Perceptions Related to Hypertension, Lifestyle BehaviorModificationsand ChallengesThat FacingHypertensive Ver. I (Nov. -Dec. 2015), PP 15-26 www.iosrjournals.org

Singh et.al (2017). Prevalence and Associated Risk Factors of Hypertension: A Cross-Sectional Study in Urban Varanasi.. doi: 10.1155/2017/5491838. 2017 Dec 3

Wanger er.al (2018). Journal Of The American College Of Cardiology .Hypertension Across a Woman'sLifeCycle. Vol. 71, NO. 16. Elsevier 
DOI: $10.47522 /$ jmk.v2i2.32

Jurnal Mitra Kesehatan (JMK)

WHO. (2019). Hypertension. diakses pada tanggal 19 Oktober 2019 dari : https://www.who.int/healthtopics/hypertension/ 